\title{
Evaluation of PRP drop and L-PRF Membrane for Aggressive Ulcerative Keratitis in Dogs
}

\author{
Apoorva Mishra ${ }^{1 *}$, Apra Shahi ${ }^{1}$, Babita Das ${ }^{1}$, Shobha Jawre ${ }^{1}$, Randhir Singh ${ }^{1}$ and Anju Nayak ${ }^{2}$ \\ ${ }^{1}$ Department of Veterinary Surgery and Radiology, College of Veterinary Science and Animal Husbandary, Nanaji Deshmukh \\ Veterinary Science University, Jabalpur, M.P., INDIA \\ ${ }^{2}$ Department of Veterinary Microbiology, College of Veterinary Science and Animal Husbandary, Nanaji Deshmukh Veterinary \\ Science University, Jabalpur, M.P., INDIA
}

"Corresponding author: A Mishra; E-mail: mishra.ap07@gmail.com

Received: 27 Nov., 2020

Revised: 02 Jan., 2021

Accepted: 08 Jan., 2021

\begin{abstract}
Melting ulcer, moderate and severe aggressive ulcerative keratitis pose a threat for staphyloma formation, perforations and blindness. The only resort to correct such condition remains corneal transplantation. Due to various shortcoming of transplantation procedure the present pilot trial was conducted to evaluate efficacy of platelet concentrates in such conditions. Platelet rich plasma drop was prepared and 1-2 drops were instilled 4 times/day for 15- 30 days in affected eye. This treatment group was compared with application of Leucocyte Platelet Rich Fibrin membrane which placed over the corneal ulcer and affixed with conjunctiva under general anesthesia. It was found that homologous PRP drops served the purpose of healing of moderate or grade II corneal ulcer satisfactorily; moreover, it prevented their advancement to severe or aggressive form. On the other hand, homologous L-PRF membrane provided sufficient scaffold for sealing of severe or grade III corneal ulcers with or without perforations and staphylomas.
\end{abstract}

\section{HIGHLIGHTS}

(0 Successful healing of aggressive ulcerative keratitis using platelet concentrates

(0 Antimicrobial activity of platelet concentrates

Keywords: Melting ulcers, aggressive ulcerative keratitis, Platelet Rich Plasma, Leucocyte Platelet Rich Fibrin and dogs

Corneal disease is the second most common cause of vision loss and blindness in dogs among which aggressive corneal ulcer and melting ulcers are the most serious affection. Ulcerative keratitis or corneal ulcer, broadly defined as any keratopathy in which there is loss of epithelium (Maggs, 2008). It is one of the most common ocular diseases which compromise visual acuity. Unattended severe cases of ulcerative keratitis can even progress to corneal scarring, degeneration and corneal blindness. Dogs suffering with aggressive ulcerative keratitis, diagnosed by opthalmoscopic examination, schirmer tear test and fluoroscene dye test were selected for present trial. All dogs suffering with stromal and melting ulcers tend to be blind and can be subjected to corneal transplantation as the last resort. Corneal transplantation in dogs is not very successful due to lack of collection system and eye bank, wound dehiscence, infection etc. Keeping all these drawbacks in mind, the present pilot study was conducted to evaluate the effect of platelet concentrates that is platelet rich plasma drops and leucocyte platelet rich fibrin membrane on aggressive ulcerative keratitis in dogs.

\section{MATERIALS AND METHODS}

Fourteen dogs with corneal ulcer were divided according

How to cite this article: Mishra, A., Shahi, A., Das, B., Jawre, S., Singh, R and Nayak, A. (2021). Evaluation of PRP drop and L-PRF membrane for aggressive ulcerative keratitis in dogs. J. Anim. Res., 11(1): 181-185. Source of Support: None; Conflict of Interest: None क क 
to the grade of ulcer into two groups viz. group I (grade II ulcers) and group II (grade III ulcers) receiving two different sets of treatment. One set of treatment consisted of administering platelet rich plasma drop and another set of treatment involved affixing leucocyte platelet rich fibrin membrane onto the corneal surface. The response to respective treatment on different grades were recorded on the basis of reduction in size and depth of ulcer, reduction in corneal oedema and vascularization

To evaluate bacterial infection and antimicrobial efficacy of platelet concentrates, swabs were aseptically collected from sample from all 14 cases of melting and stromal ulcers. It was kept in to the transport media (Phosphate Buffer Saline). Gram's staining was performed for bacteria followed by evaluating zone of inhibition (Antibiotic sensitivity test) and minimum inhibitory concentration (MIC).

\section{Preparation of homologous Platelet Rich Plasma (PRP)}

20-25 ml blood, from healthy mongrel dog, was collected into vials containing acid citrate dextrose $3.2 \%$ as anticoagulant. Centrifugation of blood was done at relative centrifuge force (RCF) of 200 gravities (g) for 10 minutes and upper layer composed of plasma platelets and WBCs (buffy coat) was collected and transferred to an empty siliconised glass tube to be homogenized. Homogenized sample was again centrifuged at RCF of $400 \mathrm{~g}$ for initial 5 minutes and subsequently at RCF of $600 \mathrm{~g}$ for another 5 minutes. The supernatant $2 / 3^{\text {rd }}$ was discarded as platelet poor plasma (PPP) and remaining $1 / 3^{\text {rd }}$ called as platelet rich plasma (PRP) was used as eye drop. PRP was stored in sterilized eppendorf tubes at $4^{\circ} \mathrm{C}$ (Kececi et al., 2014). 1-2 drops of prepared PRP was instilled 4 times/day for 15- 30 days in affected eye of group I animals.

\section{Preparation of homologous leucocyte platelet rich fibrin membrane (L-PRF)}

$10-15 \mathrm{ml}$ of blood was collected from healthy donor (mongrel dog) by venipuncture (cephalic or saphenous vein) in sterile manner. Blood obtained was placed into a sterile tube without any anticoagulant and centrifuged at $20^{\circ} \mathrm{C}$ and $2700-3000 \mathrm{rpm}$ for 10 minutes. L-PRF was formed as a clot above the red corpuscles base (Choukroun et al., 2000). It was pressed manually to form a membrane.
This L-PRF membrane was immediately placed over the corneal ulcer and affixed with conjunctiva.

The surgical procedure was performed under adequate general anaesthesia in all the animals of Group II. General anaesthesia was induced using, Inj. Atropine Sulphate (a) $0.04 \mathrm{mg} / \mathrm{kg}$ b.wt intramuscularly, after 5 minutes Inj. Xylazine hydrochloride @ $1.5 \mathrm{mg} / \mathrm{kg}$ b.wt intramuscularly and after 5 minutes Inj. Ketamine hydrochloride @ 6 mg/ $\mathrm{kg}$ b.wt intramuscularly. Maintenance of anaesthesia was done by using Inj. Ketamine hydrochloride intravenously as per the requirement. Topical anaesthesia of eye was achieved by applying a gauze soaked in Lignocaine Hydrochloride (4\%) for 5 minute.

L-PRF membrane was placed to cover the whole cornea and was affixed with conjunctiva using 4-0 polyglactin 910 suture material in group II animals. During pilot trials, after fixation of L-PRF membrane tarsorraphy sutures were removed on day 3 postoperatively to visualize the fate of L-PRF membrane. The membrane was not absorbed completely and sealing of ulcer was not visualized on this day. Thereafter, tarsorrhaphy sutures were reapplied and opened on day 7 postoperatively which revealed complete absorption of L-PRF membrane with stromal layers of melting/ aggressive ulcer.

Grading of corneal ulcer was done as per score card given by Harrison (1975) with some modification. Grading was done before the start of medication on 0 day followed by day $7,10,15,20$ and 30 post treatment.

Table 1: Grading of corneal ulcer

\begin{tabular}{|c|c|c|c|c|}
\hline \multirow{2}{*}{$\begin{array}{l}\text { Sl. } \\
\text { No. }\end{array}$} & \multicolumn{4}{|c|}{ Grading of Corneal Ulcer } \\
\hline & Features & $\begin{array}{l}\text { Mild } \\
\text { (Grade I) }\end{array}$ & $\begin{array}{l}\text { Moderate } \\
\text { (Grade II) }\end{array}$ & $\begin{array}{l}\text { Severe (Grade } \\
\text { III) }\end{array}$ \\
\hline 1 & Size & $2 \mathrm{~mm}-4 \mathrm{~mm}$ & $4-7 \mathrm{~mm}$ & $>7 \mathrm{~mm}$ \\
\hline 2 & $\begin{array}{l}\text { Depth of } \\
\text { ulcer }\end{array}$ & $<20 \%$ & $20-50 \%$ & $\begin{array}{l}>50 \% / \\
\text { descemetocele / } \\
\text { perforation }\end{array}$ \\
\hline 3 & $\begin{array}{l}\text { Stromal } \\
\text { infiltrate }\end{array}$ & $\begin{array}{l}\text { Dense and } \\
\text { Superficial }\end{array}$ & $\begin{array}{l}\text { Dense upto } \\
\text { mid-stroma }\end{array}$ & $\begin{array}{l}\text { Dense and deep } \\
\text { stromal }\end{array}$ \\
\hline 4 & $\begin{array}{l}\text { Scleral } \\
\text { involvement }\end{array}$ & NIL & $\begin{array}{l}\text { Occasionally } \\
\text { present }\end{array}$ & Present \\
\hline
\end{tabular}

Qualitative data obtained was evaluated by visual analog score and arbitrary score card (Snedecor and Cochran, 1994). 


\section{RESULTS AND DISCUSSION}

Platelet counting was performed to check the platelet count in pooled platelet rich plasma. The count was found to be 3.8 times higher than the whole blood.

Table 2: Platelet concentration in PRP

\begin{tabular}{|c|c|c|c|}
\hline $\begin{array}{l}\text { Sl. } \\
\text { No. }\end{array}$ & Donor & $\begin{array}{l}\text { Platelet count in } \\
\text { whole blood }\left(\times 10^{3} / \mathrm{ul}\right)\end{array}$ & $\begin{array}{l}\text { Platelet count in } \\
\text { pooled PRP }\left(\times 10^{3} / \mathrm{ul}\right)\end{array}$ \\
\hline 1 & 1 & 215 & \\
\hline 2 & 2 & 180 & \\
\hline 3 & 3 & 195 & \\
\hline 4 & 4 & 210 & 796 (3.8 times higher) \\
\hline 5 & 5 & 250 & \\
\hline \multirow[t]{2}{*}{6} & 6 & 192 & \\
\hline & Mean \pm & $207 \pm 10.03$ & \\
\hline
\end{tabular}

Table 3: Different types of bacterial infection in case of corneal ulcer in dogs

\begin{tabular}{llllcl}
\hline $\begin{array}{l}\text { SI. } \\
\text { No. }\end{array}$ & $\begin{array}{l}\text { Type of } \\
\text { infection }\end{array}$ & $\begin{array}{l}\text { Grams staining } \\
\text { suggestive for }\end{array}$ & No. of dogs & Per cent \\
\hline 1 & Gram & Staphylococci sps. & 04 & 06 & 42.85 \\
& positive & Streptococci sps. & 02 & & \\
2 & Mixed & - & - & 03 & 21.42 \\
3 & Gram & Bacilli & 03 & 05 & 35.71 \\
& negative & Coccobacilli & 02 & & \\
\hline
\end{tabular}

Microbiological examination of ulcerative keratitis was performed in all 14 dogs. All samples were positive for bacterial infection with Gram positive infection in $42.85 \%$ cases, mixed infection in $21.42 \%$ and Gram negative infection in $35.71 \%$ cases.

\section{In-vitro antimicrobial activity of platelet concentrates}

\section{Zone of inhibition of PRP and L-PRF against bacteria}

For determining zone of inhibition, sterile discs were taken and were dipped in Platelet rich plasma with $796 \times 10^{3} / \mathrm{ul}$ platelet count for $12 \mathrm{hrs}$. Similarly, to prepare L-PRF discs, the L-PRF membrane was triturated and sterile discs were soaked in it for $12 \mathrm{hrs}$. Discs were then dried in laminar air flow and then sensitivity test was performed.
Table 4: Zone of inhibition of platelet concentrates against different bacteria

\begin{tabular}{llllll}
\hline \multirow{2}{*}{$\begin{array}{l}\text { Sl. } \\
\text { No. }\end{array}$} & Organism N & \multirow{2}{*}{$\begin{array}{l}\text { Grams staining } \\
\text { suggestive for }\end{array}$} & \multicolumn{2}{c}{$\begin{array}{c}\text { Zone of Inhibition } \\
(\mathbf{m m})\end{array}$} \\
\cline { 4 - 6 } & & & PRP & L-PRF \\
\hline 1 & Gram & 6 & Staphylococci spp. & $32.33 \pm 5.24$ & $33.00 \pm 6.02$ \\
& Positive & & Streptococci spp. & $31.67 \pm 7.36$ & $30.33 \pm 5.78$ \\
2 & Mixed & 3 & - & $19.00 \pm 6.02$ & $17.33 \pm 5.84$ \\
3 & Gram & 5 & Bacilli & $12.50 \pm 1.50$ & $11.50 \pm 0.50$ \\
& Negative & & Coccobacilli & $12.67 \pm 0.88$ & $11.00 \pm 0.71$ \\
\hline
\end{tabular}

It was observed that Grade I ulcer mostly showed gram positive infection and they can be treated conventionally, so they were excluded from present study. Melting grade II and grade III corneal ulcer with potential threat of causing perforations and decemetocele showed heavy bacterial load on Grams staining. Zone of inhibition of both PRP and L-PRF were greater for Gram positive bacteria. The zone of inhibition of PRP against mixed culture was $19.00 \pm 6.02$ and that of L-PRF was $17.33 \pm 5.84$. Gram negative organisms were typically bacilli and coccobacilli. Zone of inhibition of PRP and L-PRF against Gram negative bacilli was $12.50 \pm 1.50$ and $11.50 \pm 0.50$ respectively and against coccobacilli was $12.67 \pm 0.88$ and $11.00 \pm 0.71$ respectively. Greater zone of inhibition of both platelet concentrates was recorded against Gram positive organism. Gram positive organisms were seen as cocci in bunches, suggestive of Staphylococcal infection or cocci in long chains, suggestive of Streptococcal infection. Zone of inhibition for the former was $32.33 \pm 5.24$ for PRP and $33.00 \pm 6.02$ for L-PRF whereas for the latter, it was $31.67 \pm 7.36$ for PRP and $30.33 \pm 5.78$ for L-PRF.

Table 5: Minimum Inhibitory Concentration of PRP against Gram positive, mixed and Gram negative infection

\begin{tabular}{lllll}
\hline \multirow{2}{*}{$\begin{array}{l}\text { Sl. } \\
\text { No. }\end{array}$} & Organism & \multicolumn{3}{c}{ PRP } \\
\cline { 3 - 5 } & & Susceptible & Resistant & $\begin{array}{l}\text { MIC (platelet } \times \\
\left.\mathbf{1 0}^{\mathbf{3}} / \boldsymbol{\mu l}\right)\end{array}$ \\
\hline 1 & Gram Positive & $6(100 \%)$ & 0 & $13.98 \pm 6.62$ \\
2 & Mixed & $3(100 \%)$ & 0 & $49.87 \pm 16.63$ \\
3 & Gram Negative & $5(100 \%)$ & 0 & $66.50 \pm 0.00$ \\
\hline
\end{tabular}

In the present study, PRP showed susceptibility towards all Gram positive bacteria, mixed infection and Gram negative bacteria with MIC of $13.98 \pm 6.62,49.87 \pm 16.63$ and $66.50 \pm 0.00$ (platelet $\left.\times 10^{3} / \mu 1\right)$, respectively. 
Both microbiological studies showed antimicrobial potential of the platelet extracts which can benefit in the present scenario of increasing antibiotic resistance. It can serve as a potential alternative medicine to combat ocular infections.

Similar finding were reported by Drago et al. (2013). The study showed antibacterial activity of P-PRP as the minimum inhibitory concentration and concluded that P-PRP inhibited the growth of Enterococcus faecalis, Candida albicans, Streptococcus agalactiae and Streptococcus oralis. Likewise, Bielecka et al. (2018) reported zones of inhibition produced by L-PRP ranged from 6 to $18 \mathrm{~mm}$ in diameter. It can be determined that L-PRP can evoke in vitro antimicrobial effects and might be used to treat selected infections in the clinical field. The study confirmed the in vitro microbicidal effect of L-PRP against methicillin-resistant Staphylococcus aureus, methicillin-sensitive Staphylococcus aureus, Enterococcus faecalis, and Pseudomonas aeruginosa. No activity of L-PRP was noted against Klebsiella pneumonia and both studied strains of Escherichia coli.

\section{Healing of ulcerative keratitis}

Post*treatment with PRP in group I animals with grade II ulcer, size of ulcerative lesion started to reduce gradually from day 7 onwards. Marked reduction was observed from day 10. It was measured as $3.6 \pm 0.50 \mathrm{~mm}$ at day 0 , which reduced $1.70 \pm 0.40 \mathrm{~mm}$ at day 10 . Progressive marked reduction was observed on day 15,20 and 30 . On day 30 complete recovery was observed in all cases. In group II animals with grade III ulcers comprising of staphyloma and perforations there was slight reduction in size of ulcer from day 0 to day 30 on treatment with PRP drops. PRP failed to heal progressive grade III corneal ulcer and causing loss of vision and fibrosis of tunics of eye with exuberant scar formation and corneal opacity.

On treatment with Leucocyte- Platelet Rich Fibrin (L-PRF) complete sealing was observed from day 7 onwards. However, prominent scar was visualized on day 10 which started to faint gradually upto day 30 .

Complete clinical healing in terms of sealing of corneal ulcer, maximum reduction of corneal opacity and vascularization was observed in $14 \pm 2.45$ and $7.00 \pm 00$ days on treatment of grade II ulcers with PRP drops L-PRF membrane, respectively. Group II with grade III ulcers showed no healing on treatment with PRP whereas on treatment with L-PRF membrane complete healing was recorded in $9.33 \pm 1.28$ days although, a whitish spot at the area of sealing of corneal ulcer was present upto day 30. On day 40 it became substantially faint but remained present.

In consonance with these findings, Kim et al. (2012) analyzed effect of autologous platelet-rich plasma on persistent corneal epithelial defect after infectious keratitis. Autologous serum was used in 17 and PRP in 11 eyes of 28 human patients. The healing rates of the corneal epithelia of the PRP-treated eyes were observed significantly higher than those treated with autologous serum. Similarly, Merlini et al. (2014) established that PRP in the form of eye drops or solid buffer is an excellent adjuvant in the treatment of corneal ulcer in dogs. The study was conducted on 19 dogs (20 eyes) and concluded that platelet activation occurs when the PRP eye drops are instilled in eyes. Therefore, in contact with the ocular surface, growth factors are released from PRP providing a prolonged effect. Complete healing of corneal ulcers was seen in 5-10 days postoperatively when treated with PRP drops and covered with third eyelid.

Table 6: Comparative reduction in size $(\mathrm{mm})$ of ulcerative lesion in different groups on treatment with PRP and L-PRF

\begin{tabular}{|c|c|c|c|c|c|c|c|}
\hline \multirow{2}{*}{ Group } & \multirow{2}{*}{ Treatment } & \multicolumn{6}{|c|}{ Reduction in size (mm) of ulcerative lesion } \\
\hline & & Day 0 & Day 7 & Day 10 & Day 15 & Day 20 & Day 30 \\
\hline \multirow[t]{2}{*}{ I (grade II ulcer } & $\operatorname{PRP}(\mathrm{n}=5)$ & $3.6 \pm 0.50$ & $2.5 \pm 0.44$ & $1.7 \pm 0.40$ & $0.70 \pm 0.20$ & $0.00 \pm 0.00$ & $0.00 \pm 0.00$ \\
\hline & L-PRF $(n=2)$ & $5.5 \pm 0.50$ & $0.00 \pm 0.00$ & $0.00 \pm 0.00$ & $0.00 \pm 0.00$ & $0.00 \pm 0.00$ & $0.00 \pm 0.00$ \\
\hline \multirow[t]{2}{*}{ II (grade III ulcer) } & $\operatorname{PRP}(n=2)$ & $10.5 \pm 1.50$ & $9.00 \pm 0.00$ & $8.75 \pm 0.25$ & $7.5 \pm 1.00$ & $6.5 \pm 0.50$ & $5.00 \pm 1.00$ \\
\hline & L-PRF $(n=5)$ & $10.0 \pm 0.86$ & $0.33 \pm 0.17$ & $0.00 \pm 0.00$ & $0.00 \pm 0.00$ & $0.00 \pm 0.00$ & $0.00 \pm 0.00$ \\
\hline
\end{tabular}




\section{CONCLUSION}

Platelet concentrates are used for various cosmetic and orthopedic treatments but their application in ophthalmology remains unexplored. From the present study it can be concluded that platelet concentrates are safe and effective in treating progressive ulcerative keratitis. In cases of decemetocele, staphylomas and other grave cases of ulcerative keratitis maximum part of cornea can be preserved by using L-PRF, so it can be used as an alternative to corneal transplantation.

\section{ACKNOWLEDGEMENTS}

Author is thankful to Head of the Department, Veterinary Surgery and Radiology, Dean, College of Veterinary Science and Animal Husbandry, Jabalpur, Department of Veterinary Microbiology, Jabalpur and other departments of the college which provided essential infrastructures required for successful completion of presented work.

\section{REFERENCES}

Bielecka, A.C., Bold, T., Ziolkowski, G., Pierchala, M., Krolikowska, A. and Reichert, P. 2018. Antibacterial activity of leukocyte and platelet-rich plasma: an in vitro study. BioMed. Res. Int., 2018: 1-8.

Choukroun, J., Adda, F., Schoeffler, C. and Vervelle, A. 2000. PRF: An opportunity in period implantology. Implantodontie, $\mathbf{4 2}$ : 55-62.
Drago, L., Bortolin, M., Vassena, C., Taschieri, S. and Fabbro, M.D. 2013. Antimicrobial activity of pure platelet rich plasma against microorganisms isolated from oral cavity. BioMed Central Microbiol., 13: 47-51.

Harrison, S.M. 1975. Grading corneal ulcers. Ann. Ophthalmol., 7(4): 537- 539.

Kim, K.M., Shin, Y.T. and Kim, H.K. 2012. Effect of autologous platelet-rich plasma on persistent corneal epithelial defect after infectious keratitis. Japanese J. Ophthalmol., 56: 544550 .

Kececi, Y., Ozsu, S. and Bilgir, O. 2014. A cost - effective method for obtaining standard platelet rich plasma. Wounds, 26: $232-238$.

Maggs, D.J. 2008. Cornea and sclera. In: Maggs, D.J., Miller, P.E., Ofri, R. and Slatter, D.H. (ed.). Slatter's Fundamentals of Veterinary Ophthalmology, $4^{\text {th }}$ Edn., Saunders, Philadelphia, pp 81-106.

Merlini, N.B., Fonzar, J.F., Perches, C.S., Sereneo, M.G., Souza, V.L., Estanislaus, C.A., Rodas, N.R., Ranzani, J.J.T., Maia, L., Padovani, C.R. and Brandao, C.V.S. 2014. Use of platelet rich plasma on corneal ulcers in dogs. Arquivo Brasileiro de Medicina Veterinaria e Zootecnia, 66: 1742-1750.

Snedecor, G.W. and Cochran, W.G. 1994. Statistical Methods. $8^{\text {th }}$ Ed., Oxford and IBH Publishing Co., Bombay, pp. 593. 
